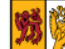

\section{A longitudinal examination of the interactive effects of goal importance and self-efficacy upon multiple life goal progress}

Beattie, S.J.; Hardy, L.J.; Woodman, Tim

\section{Canadian Journal of Behavioural Sciences}

DOI:

$10.1037 / \mathrm{a} 0039022$

Published: 06/04/2015

Peer reviewed version

Cyswllt i'r cyhoeddiad / Link to publication

Dyfyniad o'r fersiwn a gyhoeddwyd / Citation for published version (APA):

Beattie, S. J., Hardy, L. J., \& Woodman, T. (2015). A longitudinal examination of the interactive effects of goal importance and self-efficacy upon multiple life goal progress. Canadian Journal of Behavioural Sciences, 47(3), 201-206. https://doi.org/10.1037/a0039022

Hawliau Cyffredinol / General rights

Copyright and moral rights for the publications made accessible in the public portal are retained by the authors and/or other copyright owners and it is a condition of accessing publications that users recognise and abide by the legal requirements associated with these rights.

- Users may download and print one copy of any publication from the public portal for the purpose of private study or research.

- You may not further distribute the material or use it for any profit-making activity or commercial gain

- You may freely distribute the URL identifying the publication in the public portal ?

Take down policy

This article may not exactly replicate the final version published in the CPA journal. It is not the copy of record.

Take down policy

If you believe that this document breaches copyright please contact us providing details, and we will remove access to the work immediately and investigate your claim. 
14

15

6

7

8

9

0 upon multiple life goal progress

Date of submission: 22/10/2013

Article accepted for publication (12/02/2015) in the Canadian Journal of Behavioural

\section{Sciences}

Stuart Beattie, Lew Hardy, and Tim Woodman

Institute for the Psychology of Elite Performance

School of Sport, Health and Exercise Sciences

Bangor University 
Abstract

The present paper examines the interactive effects that goal importance and self-efficacy may exert upon the progress of multiple life goals. Personal goal progress in an adult sample $(N=76)$

4 were examined over a 12 week period. In accordance with previous research, it was hypothesised

5 that when goal importance is high, self-efficacy will have a positive effect upon goal progress.

6 However, when goal importance is low, self-efficacy should have a weaker effect upon goal

7 progress. Results found the hypothesised interaction between goal importance and self-efficacy.

8 Findings extend beyond previous laboratory based research where goal importance moderates the

9 positive effects of self-efficacy by examining such effects in a real life multiple goal environment. 
The effect of personal goals upon behavior has received much empirical attention (Brunstein, 1993; Elliot \& Thrash, 2002; Emmons, 1986; Little, 1989; Locke \& Latham, 1990). Personal goals have been described as "consciously articulated, personally important objectives that individuals pursue in their daily lives; they are self-investments that provide individuals with a sense of purpose, structure, and identity" (Elliot, Sheldon, \& Church, 1997, p. 915). When such goals are created, individuals are thought to focus on positive outcomes where goal orientation involves trying to reduce the discrepancy between the present state and a desired end state (Bandura, 1991; Carver \& Scheier, 1998; Powers, 1973; Vancouver, 2008).

Research investigating how individuals adopt and pursue goals has paid particular attention to self-efficacy theory (Bandura, 1986). Self-efficacy refers to the belief that one is capable of organising and executing the courses of action required to achieve desired levels of attainment. Research has shown that individuals with high levels of self-efficacy are more likely to: increase on-task effort (Bandura \& Cervone, 1983); be more committed to goals (Locke, Frederick, Lee, \& Bobko, 1984; Locke \& Latham, 1990); choose more difficult goals and tasks (Chase, 2001; Escarti \& Guzman, 1999; Waung, MacNeil, \& Vance, 1995); make greater goal progress (Sheldon \& Kasser, 1998); intensify effort when accomplishments fall short of aspirations (Peake \& Cervone, 1989); and show higher levels of task engagement (Caraway, Tucker, Reinke, \& Hall, 2003; Walker, Greene, \& Mansell, 2004). However, one limitation of self-efficacy research in relation to goals is that it has typically focused on single goal tasks (see Bandura, 1997). As such, less is known about how self-efficacy affects progress when individuals are faced with multiple goals. Bandura (1997) would argue that self-efficacy is a main precursor of goal choice, resources committed and goal progress. However, in a multiple goal environment Vancouver, Thompson, and Williams (2001) argue that "if limited 
resources are required to maintain two goals, beliefs that one goal is being met frees up resources for the other goal" (p. 617). Therefore, if individuals with high efficacy beliefs regarding goal attainment believe they are meeting their goal, they may devote less resources and commitment to that goal and instead, focus their attention on other goals that they are less confident in obtaining (especially if the other goals are personally important).

Research suggests that goal importance has its own motivational properties in relation to goal pursuits. For example, Gollwitzer (1993) asserted that goal importance influences the amount of commitment an individual will devote to their goals. Hollenbeck and Williams (1987) found that goals high in self-focus and importance were associated with higher performance (increased sales). Also, Seijts, Meertens, and Kok (1997) found a significant interaction between goal difficulty and importance with regard to public speaking; very difficult goals on important presentations led to significantly higher performance than very difficult goals on unimportant presentations. King, Richards, and Stemmerich (1998) also found a significant and positive correlation between goal importance and daily goal progress. Further, research has shown that individuals will engage in task relevant behaviours when the task is perceived to be important (e.g., Ingledew, Wray, Markland, \& Hardy, 2005; Yukl, Kim, \& Chavez, 1999; Yukle, Kim, \& Falbe, 1996).

Interactive effects between goal importance and self-efficacy have also been shown to predict goal progress. Orbell, Johnston, Rowley, Davey, and Espley (2001) investigated these interactive effects upon 32 differing physical mobility movements before and after joint (knee or hip) replacement surgery. The interaction revealed that when post-surgery self-efficacy (measured at 3 months post operation) was high, goal importance (measured pre-surgery) had a slight positive impact on overall progress measured at 9 months. However, when post-surgery self-efficacy was low, goal importance had a much stronger positive influence over progress measured at 9 months. 
1 Thus, according to Orbell et al.'s findings, self-efficacy moderates the positive effects of goal

2 importance upon goal progress. They further argued that interventions should focus on enhancing goal importance. However, self-efficacy measured pre-surgery did not interact with goal importance measured pre-surgery on overall progress (9 months post-surgery). Further, limitations exist in that Orbell et al. used an overall mean self-efficacy and goal importance score of the 32 differing activities measured, therefore competing activities in relation to self-efficacy and goal importance were not examined.

In a multiple goal environment context, Kernon and Lord (1990) examined the interactive effects of goal expectancy (estimated chances of reaching the goal) x goal valence (valence was manipulated by monetary incentive). The prediction of expectancy $\mathrm{x}$ valence theory is that goal commitment will be at its highest when both expectancy and valence are high. Further, if one is pursuing multiple goals, goals may be prioritised based on expectancy and valence beliefs. To test this theory, Kernan and Lord (1990) examined competing and multiple goals in a clerical task (e.g., selling, rotating and keeping track of stock). They found that when goals had low valence or importance, expectancy had little effect upon goal priority. However, under conditions of high goal valence (importance), as expectancy increased, goal priority increased. Therefore, goal importance (or valence) moderated the effect of outcome confidence on progress in a multiple goal environment. However, in their multiple goal condition, Kernan and Lord (1990) only examined two competing goals and under laboratory conditions. Further, Kernan and Lord only examined goal priority over a very short period of time (approx. 30 minutes) and much less are known about how valence and expectancy influence goal progress over a sustained period of time. Recent research that have further examined multiple goals also use the dual goal/task paradigm in a lab setting under short durations (e.g., Schmidt \& DeShon, 2007; Schmidt, Dolis, \& Tolli, 2009; 
1 Vancouver, Weinhardt, \& Schmidt, 2010). Hence, testing the valence expectancy model by

2 extending the dual goal paradigm task in a longitudinal study using actual life goals is warranted.

3 A further strength of using real life goals is that real life will impose various constrictions on goal

4 choice that will also influence goal progress. Further, participants are completely free to choose amongst their own goals rather than being constrained by laboratory assignments. For example, an individual may choose goals that they want to pursue, or goals that they need to pursue (e.g., Austin \& Vancouver, 1996) rather than completing an assigned laboratory task.

The present study only set to examine the interactive effects of self-efficacy and goal importance in a multiple goal environment with adult life goals over a 3 month period. According to a valence-expectancy models (e.g., Kernan \& Lord, 1990) goal importance should interact with self-efficacy to predict goal progress. Specifically, when goal importance is low, self-efficacy should have little effect upon goal progress (as important goals are prioritised). However, when goal importance is high, self-efficacy should have a strong and positive effect upon goal progress.

\section{Participants} in the study. They ranged in age from 20 to 70 years, mean $=39.4, \mathrm{SD}=14.5$. All participants gave informed consent prior to data collection. Participants were contacted and recruited through postgraduate students who were paid $£ 5$ per completed participant. Although the participants were not paid for their time, they were provided with the opportunity for feedback concerning their individual goal diary and the results of the study. Of the 102 participants, 76 (35 Men, 41 Women, mean age $=39.3$ years, $\mathrm{SD}=14.6)$ completed the survey at Time 1 and also reported on goal 
$1 \quad(1)=7.43, \mathrm{~N}=102, \mathrm{p}=.006, \mathrm{~V}=.27$. Information on participants' education, social class, and

2 ethnicity was not collected.

3 Measures

Personal Project Analysis. A modified version of Little’s (1983) Personal Project Analysis (PPA) was used to record goals, goal importance, and goal progress. On the first page, the instructions for completing the PPA were slightly extended from Little (1983) and read:

We are interested in studying the kinds of personal projects that people have at different stages of their life. All of us have a number of personal projects at any given time that we think about, plan for, carry out, and sometimes (though not always) complete. Please think about the projects or goals that you are currently working on.

We then provided participants with some examples of goals, such as: "Being more successful in my relationships"; "Finding a full time job."

On the second page, participants wrote down all the goals that they were currently working toward or thinking about working toward in the near future. On the third page, they were instructed to write out the five goals that they were most likely to engage in over the subsequent three months. We only asked for five goals to be rated in order to gain maximum recruitment retention. Alongside this, goal importance ("How important to you at the present time is each goal?") and goal progress (“How much progress have you made so far with your goal?)" were measured. Responses were made on a 11 -point Likert scale $(0=$ not at all important/no progress to $10=$ extremely important/most progress).

Personal Project Self-efficacy. Participants rated their self-efficacy regarding the attainment of each goal. We used a slightly modified version of self-efficacy measures used in previous studies (e.g., Sheldon \& Kasser, 1998). Self-efficacy magnitude was recorded by asking the participants to 
1 rate whether they had the skills and resources to perform at 10 different levels for each goal (i.e., "I

2 have the skills and resources to be $10 \%$ successful at achieving this goal"; "I have the skills and

3 resources to be $20 \%$ successful at achieving this goal"; until "I have the skills and resources to be

$4 \quad 100 \%$ successful at achieving this goal"). Thus, a magnitude score of 0 to 100 (in increments of 10)

5 could be recorded for each project (i.e., if an individual reported yes to the first 7 levels, he/she was

6 attributed a score of $70 \%)$.

7 Self-efficacy strength was recorded by asking the participants to, "Rate your degree of

8 confidence in being able to attain this level of performance on a scale of $0-100 \%$. That is, for each

9 magnitude level that the respondent answered yes to, they had to rate how confident they were of

10 obtaining that level of performance. However, as self-efficacy strength results mirrored the findings

11 to that of self-efficacy magnitude, only self-efficacy magnitude results are subsequently reported.

\section{Procedure}

13 After initial contact was made further information with regards to the nature of the study were provided. After agreement and consent was granted to participate in the study, the PPA was sent out to the participant that included all measures (i.e., current goal progress, importance and selfefficacy) and was returned via pre-paid envelopes. Goal progress was assessed again 12 weeks later. The final PPA was returned via pre-paid envelope.

\section{Analysis}

As goals were nested within participants hierarchical linear modelling (HLM; Raudenbush \& Bryk, 2002) Version 7 was used. Nested data structures make single-level regression analyses problematic (Beck \& Schmidt, 2012). The advantage of linear modelling is that it allows the estimate of individual slopes and intercepts for each Level-2 unit (i.e., participants) across Level-1 units (e.g., goal progress, self-efficacy and goal importance). All variables were treated as random 
1 effects (see Barr, Levy, Scheepers, \& Tily, 2012). Further, person (group) mean centering was used

2 for all variables. Progress at Time 2 was used as the outcome variable within the model. The

3 following predictor variables were entered in the following order: (1) Progress at Time 1; (2) Self-

4 efficacy; (3) Goal importance; and (4) Self-efficacy x Importance interaction term.

Results

\section{Self-efficacy and goal importance predicting goal progress}

The 76 participants provided a total of 375 goals $(M=4.9$ goals per participant $)$. A variety of types of goals were reported by the participants (e.g., "Pass my driving test"; "Have a successful wedding day"; "Find a full time job"; Recover from cancer"; "Save for a holiday"; "Stick to my diet and lose weight"; "Pass my exams"; "Get out of debt"; "Get more exercise"; "Be a better parent" and "To take better care of my parents").

Table 1 shows the means, standard deviations and average bivariate correlations and intraclass correlations among the study variables. To examine the between person correlations, all correlations were based upon the 76 cases. That is all data was averaged within person before correlations were calculated. Across participants, progress at Time 1 and goal importance significantly correlated with progress at Time 2 . However, self-efficacy failed to significantly correlate with progress at Time 2 . Before computing the interaction term, each variable (goal importance, self-efficacy, and goal progress at Time 1 and Time 2) was standardized across participants (Jaccard, Turrisi, \& Wan, 1990). To examine if multilevel modeling was appropriate, the proportion of variance that was accounted for by the between group effect (across level 2 units i.e., participants) intraclass correlations (ICC) were calculated for all variables (see Table 1). As shown in Table 2, goal progress at Time 1 significantly predicted goal progress at Time 2. 
1 importance significantly predicted later goal progress above progress at Time 1 and self-efficacy.

2 Finally, the product term (self-efficacy $\mathrm{x}$ importance) significantly predicted variance in goal progress at Time 2 over and above the main effects (see Table 2 and Figure 1). Figure 1 shows that when goal importance is high self-efficacy has a positive relationship upon goal progress, but when goal importance is low, self-efficacy appears to play no role in goal progress. To examine any potential gender and age effects, the HLM analyses was rerun with gender and age as a level 2 variable. However, no moderating effects occurred.

\section{Discussion}

The purpose of the present study was twofold. First, we sought to re-test previous research in multiple goal environments by examining the interactive effects of self-efficacy and goal importance (e.g., Kernan \& Lord, 1990; Orbell et al., 2001) using actual life settings as opposed to lab settings. Second, we extended the number of goals usually examined from 2 to 5 and examined goal progress over a 3 month period. According to Bandura $(1977,1986)$ high levels of selfefficacy should be a strong and significant predictor of goal progress. However, previous research has shown that goal importance (valence) may moderate that relationship (e.g., Kernan \& Lord, 1990). Results found a significant two-way interaction between goal importance and self-efficacy where self-efficacy only had a positive effect upon goal progress when goals were important. Interestingly, no progress was made on unimportant goals over the course of the 3 month period regardless of self-efficacy levels. These results support that of valence expectancy models in a multiple goal environment (e.g., Kernan \& Lord, 1990).

At the between person level, self-efficacy failed to significantly correlate with progress at Time 2. However at a within person level, support for self-efficacy theory was shown in that selfefficacy magnitude significantly predicted goal progress at Time 2 above that of goal progress at 
1 Time 1 and accounted for $9 \%$ of the variance. This finding also supports a within person effect, in

2 that self-efficacy predicted a significant amount of variance upon subsequent performance when

3 previous performance accomplishments were accounted for (Bandura, 2012). However, the

4 interaction showed that this effect only occurred under high goal importance. It seems that when

5 goals are less important self-efficacy loses its positive effect. Goal importance significantly

6 predicted goal progress at Time 2 above that of previous progress and self-efficacy and accounted

7 for an additional $17 \%$ of the variance. Further, Table 1 shows that goal importance and self-efficacy

8 demonstrated a high level of discriminant validity with a correlation of $r=.06$. Thus the present

9 study adds further support that goal importance or valence should be regarded as an important

10 variable in influencing goal progress.

The interaction in the present study also differed to that of Orbell et al. (2001) findings.

Orbell et al. found that high levels of self-efficacy had a strong impact upon progress in mobility regardless of goal importance. In the present study, self-efficacy only had a positive effect upon goal progress when goal importance was high. There are two major differences between the present study and that of Orbell et al. First, Orbell et al. did not examine competing goals as they summed self-efficacy and goal importance scores across 32 functional activities. This provides one score for each independent variable at each time point (in essence reducing their data set from 32 functional activities to an overall mean function activity score). Secondly, Orbell et al. examined self-efficacy and goal importance over various time points from 2 weeks pre-surgery to 3 and 9 months postsurgery. Their interaction occurred with goal importance measured pre-surgery and self-efficacy measured 3 months post-surgery. In this case, self-efficacy beliefs measured 3 months post-surgery, would have been strongly influenced by progress over those 3 months. However, it is also unclear in the present study how long participants were engaged with their current goals in order to make 
accurate self-efficacy judgements. As Bandura (1997) states, "the goals people set for themselves at the outset of an endeavour are likely to change, depending on how they construe the pattern and level of progress they are making" (p. 129). It is therefore likely that previous experiences combined with fluctuations in subsequent self-efficacy beliefs and goal importance across time will determine how strong the moderation may be. Therefore, to further clarify the present findings multiple time points should be used to examine such possible fluctuations across time.

Although goal importance significantly predicted progress over and above self-efficacy, research suggests that this may not be the sole variable to do so. For example, Sheldon and Kasser (1998) found that social and self-regulatory skills were more strongly related to goal progress than self-efficacy. Recent research also shows that goal discrepancies, expectancies, and difficulty also show dynamic relationships in a multiple goal domain (e.g., Schmidt \& Dolis, 2009; Schmidt et al., 2009; Vancouver et al., 2010). For example, Schmidt et al. (2009) found that in a dual goal environment, if the task was not completely in the control of the participants (volatile), more time was allocated to whichever goal was most discrepant (if time was not an issue). However, if time ran short, participants in the volatile environment allocated more time to the least discrepant goal.

Other research suggests that ability, control, enjoyment, feedback, importance to others, measurability, success expectations and goal value are also positively linked to goal commitment (Ingledew et al., 2005). Future research should also consider how these later variables may interact in predicting goal commitment and engagement.

Future research should also further consider the motivational reasons for goal choice. For example, the self-efficacy ratings in the present study may only relate to predictions of achievement but not directly causing the achievement. This is in line with Hawkins (1992) who asserts that selfefficacy may be a predictor of behaviour but not necessary a cause, in that, "self-efficacy is not 
suddenly present 'de novo' but has been determined by prior events” (p. 255). In other words, goal engagement can occur regardless of efficacy beliefs (e.g., Austin \& Vancouver, 1996). It's highly probable that people choose to pursue goals for a variety of reasons some of which are mentioned in the previous paragraph. Perhaps the reason for pursuing a goal would be its strongest predictor of goal progress (be it efficacy expectation, importance, needs or any other form of motivation).

Further studies are warranted to examine the possible moderating role of goals that one needs to engage with rather than those that one wants to engage with (e.g., Austin \& Vancouver, 1996). For example, the goal of "Pass my driving test" may be embedded as a need goal (I need a license in order to get a job) or a want goal (I want my license in order to gain more freedom) or indeed a mix of both. If the person is pursuing such a goal and perceives it as a need (i.e., to get a job), then clearly self-efficacy is not a cause of goal choice and even less likely to relate to goal progress. Therefore, a need goal may also be a moderating variable in the self-efficacy and progress relationship. However, if it is a want goal, it is likely that the person may engage and disengage with it across time irrespective of importance (as attention is drawn to other important goals) but efficacy may play a more influential role. However, it was not possible to further examine the possible moderating effect of needs and wants as it is difficult to determine the underlying reasons for goal choice in the current study.

To sum, the present study specifically set out to test and extend Kernan and Lord's (1990) study to examine the interactive effects of goal importance and self-efficacy in a real life setting, using a higher number of personal goals across a longer time frame. Limitations of the present study are that self-efficacy expectations in regard to goal attainment were only measured at the start of the study and may have significantly changed over the 3 months, which may have influenced their relationship with goal progress. Therefore, future studies should take fluctuations in self- 
1 efficacy levels and importance across time into consideration. Another limitation is that goal

2 discrepancies were not accounted for. For example, in highly volitional goal environments, when

3 time is of the essence attention are generally driven to goals with the smallest discrepancy (e.g.,

4 Schmidt et al., 2009). It should be acknowledged that as discussed, there are a large number of

5 'other' moderating variables that influence the self-efficacy and performance relationship. Finally,

6 it should be noted that no information was gathered about social class, education, ethnicity, income,

7 employment etc. that may influence the resources that one has at their disposal. For example, many

8 of the goals reported require a financial contribution where income and employment would enhance

9 goal progress. However, it is likely that participants set goals that were within their means and the

10 goals that they set were perhaps reflective of their current situation.

11 The purpose of this study was only to examine Kernan and Lord's (1990) model in real life

12 where numerous amount of choices exist and where numerous other variables impose upon goal

13 progress. Replicating such findings is a testament to such models. Finally, the present study only

14 examined growth trajectories over 2 time points (albeit 3 months apart) which may be inadequate

15 for examining growth over time (Raudenbush \& Bryk, 2002). Future research should consider

16 multiple time points to examine growth. To conclude, strong support was shown for valence

17 expectancy model of behaviour in that self-efficacy combined with high goal importance had a strong and positive influence upon progress. 


\section{References}

Bandura, A. (1977). Self-efficacy: Toward a unifying theory of behavioral change. Psychological Review, 84, 191-215. DOI:10.1037/0033-295X.84.2.191

Bandura, A. (1986). Social foundations of thought and action: A social cognitive theory. Englewood Cliffs, NJ: Prentice-Hall.

Bandura, A. (1991). Self-regulation of motivation through anticipatory and self-regulatory mechanisms. In R. A. Dienstbier (Ed.), Perspectives on motivation: Nebraska symposium on motivation (Vol. 38, pp. 69-164). Lincoln: University of Nebraska Press.

Bandura, A. (1997). Self-efficacy. New York: Freeman.

Bandura, A. (2012). On the functional properties of perceived self-efficacy revisited. Journal of Management, 38, 9-44. DOI:10.1177/0149206311410606

Bandura, A., \& Cervone, D. (1983). Self-evaluative and self-efficacy mechanisms governing the motivational effects of goal systems. Journal of Personality and Social Psychology, 45, 10171028. DOI: $10.1037 / / 0022-3514.45 .5 .1017$

Barr, D.J., Levy, R., Scheepers, C., \& Tily, H. J. (2013). Random effects structure for confirmatory hypothesis testing: Keep it maximal. Journal of Memory and Language, 68, 255-278

Beck, J. W, \& Schmidt A. M. (2012). Taken out of context? Cross-level effects of between person self-efficacy and difficulty on the within-person relationship of self-efficacy with resource allocation and performance. Organizational Behavior and Human Decision Processes, 119, 195-208. DOI.10.1016/j.obhdp.2012.06.009

Brunstein, J. C. (1993). Personal goals and subjective well-being: A longitudinal study. Journal of Personality and Social Psychology, 65, 1061-1070. DOI: 10.1037//0022-3514.65.5.1061

Caraway, K., Tucker, C. M., Reinke, W. M., \& Hall, C. (2003). Self-efficacy, goal 
orientation, and fear of failure as predictors of school engagement in high school students. Psychology in the Schools, 40, 417-427. DOI: 10.1002/pits.10092

Carver, C. S., \& Scheier, M. F. (1998). On the self-regulation of behavior. New York: Cambridge University Press.

Chase, M. A. (2001). Children's self-efficacy, motivation intentions, and attributions in physical education and sport. Research Quarterly for Exercise and Sport, 72, 47-54.

Elliot, A. J., Sheldon, K. M., \& Church, M. A. (1997). Avoidance personal goals and subjective well-being. Personality and Social Psychology Bulletin, 23, 915-927. DOI: $10.1177 / 0146167297239001$

Elliot, A. J., \& Thrash, T. M. (2002). Approach-avoidance motivation in personality: Approach and avoidance temperament and goals. Journal of Personality and Social Psychology, 82, 804818. DOI: $10.1037 / 0022-3514.82 .5 .804$

Emmons, R. A. (1986). Personal strivings: An approach to personality and subjective well-being. Journal of Personality and Social Psychology, 51, 1058-1068. DOI: 10.1037//00223514.51.5.1058

Escarti, A., \& Guzman, J. F. (1999). Effects of feedback on self-efficacy, performance, and choice on an athletic task. Journal of Applied Sport Psychology, 11, 83-96. DOI: $10.1080 / 10413209908402952$

Gollwitzer, P. M. (1993). Goal achievement: The role of intentions. In M. Hewstone \& W. Stroebe (Eds.), European Review of Social Psychology (Vol. 4, pp. 141-185). Chichester, England: Wiley.

Hawkins, R. (1992). Self-efficacy: A predictor but not a cause of behaviour. Journal of Behavior Therapy and Experimental Psychiatry, 23, 251-256. DOI: 10.1016/0005-7916(92)90047-M 
Hollenbeck, J. R., \& Williams, C. R. (1987). Goal importance, self-focus, and the goal-setting process. Journal of Applied Psychology, 72, 204-211. DOI: 10.1037//0021-9010.72.2.204

Ingledew, D. K., Wray, J. L., Markland, D., \& Hardy, L. (2005). Work-related goal perceptions and affective well-being. Journal of Health Psychology, 10, 101-122. DOI: $10.1177 / 1359105305048558$

Jaccard, J., Wan, C. K., \& Turrisi, R. (1990). The detection and interpretation on interactive effects between continuous variables in multiple regression. Multivariate Behavioral Research, 25, 467-478.

Kernan, M. C., \& Lord, R. G. (1990). Effects of valence, expectancies, and goal-performance discrepancies in single and multiple goal environments. Journal of Applied Psychology, 75, 194-203. DOI: 10.1037/0021-9010.75.2.194

King, L. A., Richards, J. H., \& Stemmerich, E. (1998). Daily goals, life goals, and worst fears: Means, ends, and subjective well-being. Journal of Personality, 66, 713-744. DOI: $10.1111 / 1467-6494.00030$

Little, B. R. (1983). Personal projects: A rational and method for investigation. Environment and Behavior, 15, 273-309. DOI: 10.1177/0013916583153002

Little, B. R. (1989). Personal projects analysis: Trivial pursuits, magnificent obsessions, and the search for coherence. In D. M. Buss \& N. Cantor (Eds.), Personality Psychology: Recent trends, emerging directions (pp. 15-31). New York: Springer-Verlag.

Locke, E. A., Frederick, E., Lee, C., \& Bobko, P. (1984). Effect of self-efficacy, goals, and task strategies on task performance. Journal of Applied Psychology, 69, 241-251. DOI: 10.1037/0021-9010.69.2.241

Locke, E. A., \& Latham, G. P. (1990). A theory of goal setting and task performance. Englewood 


\section{Cliffs, NJ: Prentice-Hall.}

Orbell, S., Johnston, M., Rowley, D., Davey, P., \& Espley, A. (2001). Self-efficacy and goal importance in the prediction of physical disability in people following hospitalization: A prospective study. British Journal of Health Psychology, 6, 25-40. DOI: $10.1348 / 135910701169034$

Peake, P. K., \& Cervone, D. (1989). Sequence anchoring and self-efficacy: Primacy effects in the consideration of possibilities. Social Cognition, 7, 31-50. DOI: 10.1521/soco.1989.7.1.31

Powers, W.T. (1973). Behaviour: The control of perception. New York: Hawthorne.

Raudenbush, S. W., \& Bryk, A. S. (2002). Hierarchical linear models: Applications and data analysis methods. CA: Sage Publications.

Schmidt, A. M., \& DeShon, R. P. (2007). What to do? The effects of discrepancies, incentives, and time on dynamic goal prioritization. Journal of Applied Psychology, 92, 928941. DOI: $10.1037 / 0021-9010.92 .4 .928$

Schmidt, A. M., Dolis, M. C. (2009). Something's got to give: The effects of dual-goal difficulty, goal progress, and expectancies on resource allocation. Journal of Applied Psychology, 94, 678-691. DOI: 10.1037/a0014945

Schmidt, A. M., Dolis, M. C., \& Tolli, A. P. (2009). A matter of time: Individual differences, contextual dynamics, and goal progress effects on multiple-goal self-regulation. Journal of Applied Psychology, 94, 692-709. DOI: 10.1037/a0015012

Seijts, G. H., Meertens, R. M., \& Kok, G. (1997). The effects of task importance and publicness on the relation between goal difficulty and performance. Canadian Journal of Behavioural Science, 29, 54-62. DOI: 10.1037/0008-400X.29.1.54

Sheldon, K. M., \& Kasser, T. (1998). Pursuing personal goals: Skills enable progress but not all 
progress is beneficial. Personality and Social Psychology Bulletin, 24, 1319-1331. DOI: 10.1177/01461672982412006

Vancouver, J. B., (2008). Integrating self-regulation theories of work motivation into a dynamic process theory. Human Resource Management Review, 18, 1-18. DOI: 10.1016/j.hrmr.2008.02.001

Vancouver, J. B., Thompson, C. M., \& Williams, A. A. (2001). The changing signs in the relationship among self-efficacy, personal goals, and performance. Journal of Applied Psychology, 86, 605-620. DOI: 10.1037//0021-9010.86.4.605

Vancouver, J. B., Weinhardt, J. M., \& Schmidt, A. M. (2010). A formal computational theory of multiple-goal pursuit: Integrating goal-choice and goal striving process. Journal of Applied Psychology, 95, 985-1008. DOI: 10.1037/a0020628

Walker, C. O., Greene, B. A., \& Mansell, R. A. (2004). Identification with academics, intrinsic/extrinsic motivation, and self-efficacy as predictors of cognitive engagement. Learning and Individual Differences, 16, 1-12. DOI: 10.1016/j.lindif.2005.06.004

Waung, M., MacNeil, M., \& Vance, R. J. (1995). Reactions to feedback in goal choice and goal change process. Journal of Applied Social Psychology, 25, 1360-1390. DOI: 10.1111/j.15591816.1995.tb02622.x

Yukl, G., Kim, H., \& Chavez, C. (1999). Task importance, feasibility, and agent influence behaviour as determinants of target commitment. Journal of Applied Psychology, 84, 137143. DOI: $10.1037 / / 0021-9010.84 .1 .137$

Yukl, G., Kim, H., \& Falbe, C, M. (1996). Antecedents of influential outcomes. Journal of Applied Psychology, 81, 309-317. DOI: 10.1037//0021-9010.81.3.309 
2

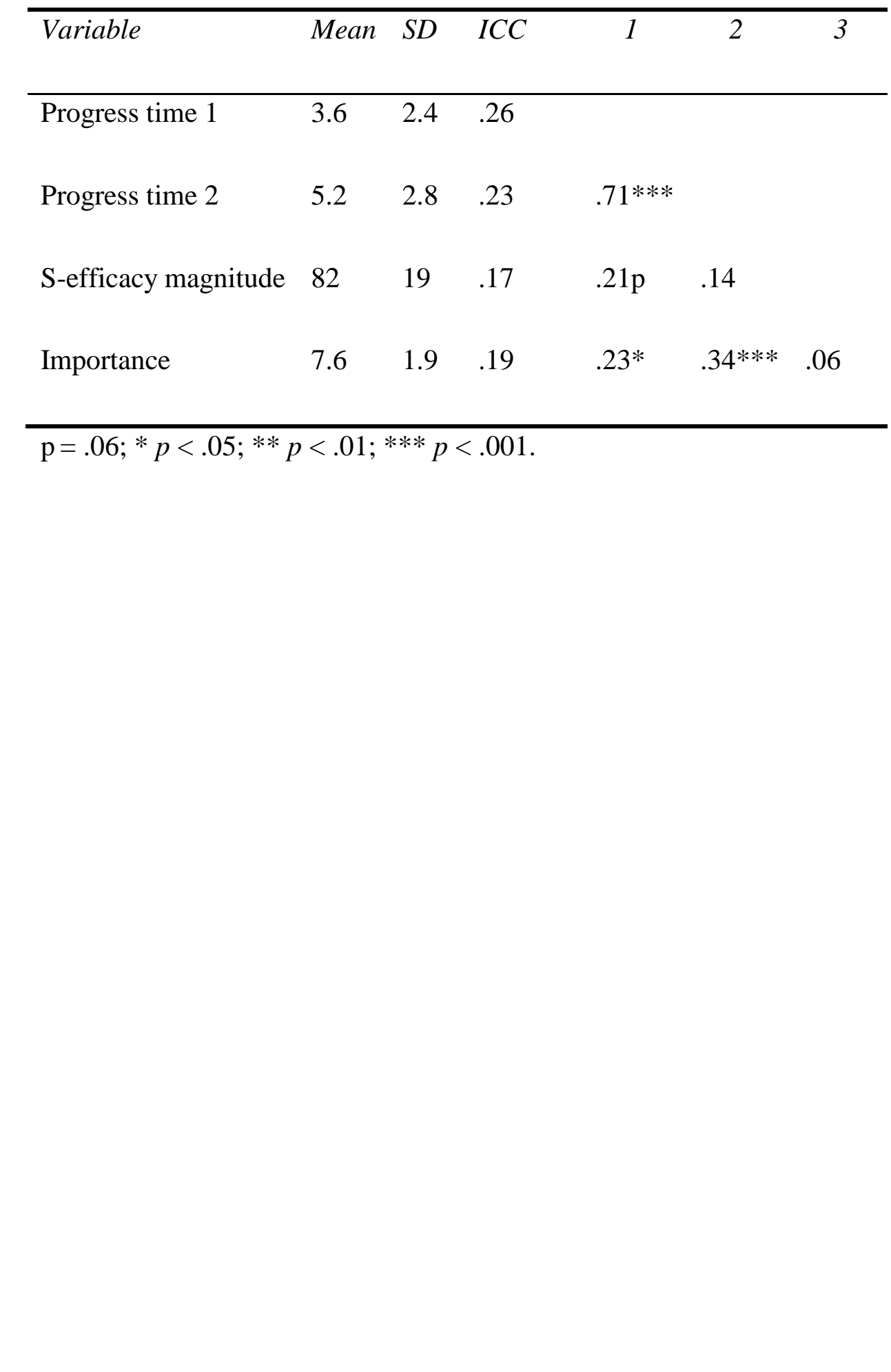


Step-wise main and interactive effects of the average level-one regression coefficients (i.e., gamma values) upon goal progress at Time 2.

Progress at time 2 as an outcome variable

\begin{tabular}{lccccc}
\multicolumn{1}{c}{ Step } & $\gamma$ & $\mathrm{SE}$ & $\mathrm{df}$ & $\%$ Var & $\Delta \%$ Var \\
\hline 1. Progress at time 1 & $0.56^{* * *}$ & .06 & 75 & 34 & \\
\hline 2. Self-efficacy magnitude & $0.12^{*}$ & .05 & 75 & 40 & 9 \\
\hline 3. Goal importance & $0.19^{* *}$ & .04 & 75 & 50 & 17 \\
\hline 4. S-efficacy x Importance & $0.12^{* *}$ & .04 & 75 & 54 & $9^{1}$ \\
\hline
\end{tabular}

$* p<.05 ; * * p<.01 ; * * * p<.001$.

\footnotetext{
${ }^{1}$ The reader will note that there are discrepancies between the total variance accounted for and the delta variances. Although it isn't possible to obtain a true R-squared value in HLM, it is possible to obtain an estimate. The total level 1 variances are calculated by the following recommended method (unrestricted error - restricted error) / unrestricted error. The delta variances are calculated by for example (restricted error 1 - restricted error 2) / restricted error 1). Therefore, these variances should be interpreted with caution and as an estimation of total variance that may be explained not absolute.
} 


\section{Figure Captions}

Figure 1. Regression slopes $( \pm 1 S D)$ showing the moderating effects of goal importance upon self-efficacy and goal progress.

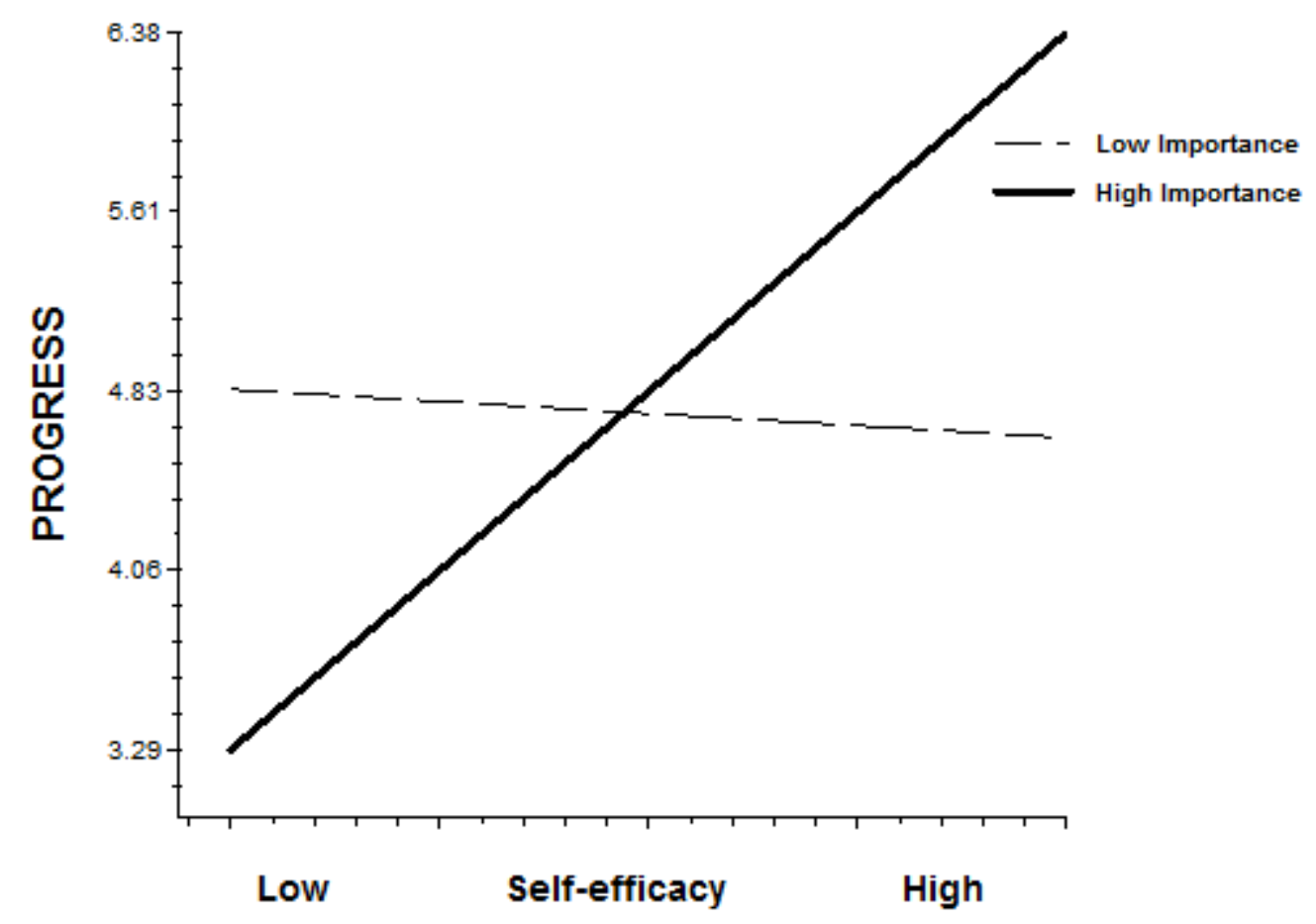

